\title{
INDICACIONES Y MORBIMORTALIDAD DE LA NEFRECTOMÍA ABIERTA. ANÁLISIS DE 681 CASOS Y REVISIÓN DE LA LITERATURA.
}

\author{
Juan José Ballesteros Sampol
}

Servicio de Urología y UQTR del Hospital Nuestra Señora de la Esperanza. Barcelona. España.

\begin{abstract}
Resumen.- OBJETIVO: Conseguir datos sobre indicaciones, morbilidad y mortalidad de la nefrectomía por cirugía abierta para obtener información contrastable con lo que, hoy en día, es factible realizar por cirugía laparoscópica. Hasta donde conocemos no se ha publicado ningún estudio similar en la literatura española especializada tras la revisión del tema desde la década de los 60 hasta nuestros días.
\end{abstract}

MÉTODOS: Se analizan 681 casos de "nefrectomías" que suponen el 5,7\% de un total de 17.845 hojas operatorias registradas en nuestro centro en los últimos 25 años. Para valorar resultados se excluyen por razones obvias 93 cirugías de extracción renal de donante cadáver. El análisis se centra en tres áreas bien diferenciadas: cirugía del trasplante renal, nefrectomías por procesos malignos y nefrectomías por patologías benignas con un subgrupo muy específico integrado por las patologías infeccioso-inflmatorias. Paralelamente se revisa la literatura en la que se referencian más de 87.000 casos de cirugías abiertas y se añaden las publicaciones que sobre nefrectomías laparoscópicas se han producido en los últimos lustros.

RESULTADOS/CONCLUSIONES: La mortalidad global de la serie (30 días post cirugía) ha sido del 0,8\% y corresponde mayoritariamente a casos trasplantectomizados (cuatro) y a un tumor de vía excretora. Por otro lado la morbilidad significativa ha alcanzado 47 casos (8\%) de los que precisaron reintervención $15(2,5 \%)$ siendo la causa más importante y frecuente dentro de estas reintervenciones la hemorragia profunda con hipovolemia de gravedad variable. Como es lógico esta serie se nutre de casos en absoluto seleccionados y con un amplio espectro de patologías. Cualquier comparación con técnicas de acceso mínimo deberá tener en cuenta, entre otros parámetros, la selección o no de los casos.

Palabras clave: Cirugía abierta. Nefrectomía abierta. Nefrectomía laparoscópica. Complicaciones.

Summary.- OBJECTIVES: To have data about the indications, morbidity and mortality of the nephrectomy by the open approach, to obtain information that could be compared with the laparoscopic approach. To our knowledge there is not a similar review in the Spanish literature since this 60's.

METHODS: We analyzed 681 nephrectomies accounting for a $5.7 \%$ of a total of 11.845 operative reports registered in our centre over the last 25 years. For outcome analysis, 93 cadaver donor nephrectomies were excluded. The analysis focuses on three well differentiated areas: 
kidney transplant surgery, nephrectomies for malignant diseases, and nephrectomies for benign pathologies including a very specific subgroup that includes the infectious-inflammatory diseases. In parallel, we performed a bibliographic review in which more than 87,000 cases of open surgeries where referenced, adding the articles about laparoscopic nephrectomies published over the last decade.

RESULTS: Global mortality of the series (the first 30 postoperative days) was $0.8 \%$, mostly cases of transplant nephrectomies (4), and one upper urinary tract transitional cell carcinoma. Significant morbidity appeared in 47 cases (8\%), 15 of which (2.5\%) required reoperation, being intensive bleeding with hypovolemia of variable severity the most frequent cause.

The series includes non selected cases of a wide spectrum of pathologies. Any comparison with minimally invasive approaches should take into consideration, among other parameters, selection of the cases.

Keywords: Open surgery. Open nephrectomy. Laparoscopic nephrectomy. Complications.

\section{INTRODUCCIÓN}

La reciente aparición de la cirugía laparoscópica en Urología y su imparable desarrollo desde la realización de la prostatectomía radical plantea algunos interrogantes que la revisión de etapas históricas de la cirugía abierta puede ayudar a resolver. Aunque al día de hoy existe una cierta prudencia en establecer las indicaciones de la cirugía laparoscópica (C.L.) no es menos cierto que se van superando limitaciones hasta hace poco firmes y resistentes. En efecto, aunque las indicaciones actuales se nutren especialmente de patologías "benignas" o malignas de volumen "limitado", existe un especial "prurito" profesional entre las diferentes unidades por subir un peldaño más cada vez (1) y llegar a realizar lo que "aún no ha hecho nadie". Tras más de 35 años en esta especialidad quirúrgica puedo decir que ese "prurito" ha existido siempre y siendo "bueno" en su origen no debe hacernos perder el norte razonable de su aplicación ya que no debemos olvidar que quien puede pagar las consecuencias de nuestras "ansias" es un ser humano.

Es, pues, en este sentido que entiendo útil saber lo que nos ocurrió con esta cirugía cuando la única opción era el acceso abierto y a la que, en esos años, sólo se la limitaba por condiciones del estado general del paciente y comorbilidades serias.
La nefrectomía por "tumor" inicia su etapa histórica (2) en 1861 cuando Wolcott extirpa este órgano asiento de una neoplasia aunque la cirugía se había indicado por un "quiste hepático". En 1876 Kocher realizó la nefrectomía transperitoneal con el diagnóstico preoperatorio correcto. Tanto uno como otro paciente fallecieron por peritonitis a los 3 días. En 1902 Kuster realiza una primera evaluación de estas intervenciones transperitoneales encontrando una mortalidad elevada del $34 \%$. La consecuencia fue que, desde 1902, se fuera realizando la intervención por vía retroperitoneal preconizada por Cabot (3), Young y Davis (4). Este interés se vió acrecentado desde la recomendación de Poutasse de la vía subcostal para el acceso al riñón y sus vasos (5). En 1905 Gregoire, citado por Murphy, propone el concepto de "nefrectomía radical" incluyendo grasa, capsula, linfáticos y suprarrenal. En 1929, Judd y Hand (6) recomiendan un detalle fundamental de esta cirugía como es la ligadura previa del pedículo renal pero no es hasta 1963 cuando Robson implanta el control previo del pedículo renal y la exéresis en bloque a través de una incisión toracoabdominal con linfadenectomía que hicieron que el concepto de nefrectomía radical fuera ampliamente asumido a la vista de sus resultados publicados seis años más tarde (7).

\section{MATERIAL Y MÉTODO}

Hemos revisado 11.845 hojas operatorias del Servicio de Urología de las que se han entresacado 681 por nefrectomías cuyas indicaciones se expresan en la Tabla I. Al objeto de valorar complicaciones y mortalidad se han restado las 93 extracciones de riñones de donante cadáver (en más de la mitad de los casos, extracciones múltiples) realizadas por vía transperitoneal, bien laparotomía media, en "chevron" bilateral o en estrella. La sustracción de tales casos es obvia en función de la finalidad del artículo. Sin embargo es también interesante el análisis de las visicitudes de estas extracciones y su posible influencia en el posterior trasplante lo que ya fue tratado en una anterior publicación (8).

Así pues nos quedamos con 588 nefrectomías que hemos agrupado en tres áreas básicas: cirugía del trasplante renal (TR) (nefrectomía de donante vivo, nefrectomías de riñón homolateral atrófico en el mismo acto del T.R. y, sobre todo trasplantectomías) con 182 casos; nefrectomías de patologías tumorales malignas(sólidos de parénquima renal y tumores de vías) con 177 y, nefrectomías de patologías benignas que con 229 casos cubre un amplio mosaico de indicaciones entre las que debemos destacar las de causa infeccioso inflamatoria no específica con 128 cirugías. 
El primer punto a analizar es el de la mortalidad operatoria entendiendo como tal la que, por cualquier causa, acaece dentro de los 30 días siguientes a la cirugía o durante período en que el paciente ha estado ingresado aunque superara esa fecha. Cinco han sido los pacientes fallecidos lo que supone un $0,8 \%$ (Tabla II). Llama claramente la atención que cuatro de los cinco casos han sido pacientes trasplantados a los que se les indicó trasplantectomía por fracaso funcional del injerto agudo o crónico. A este respecto tenemos que decir que la política de nuestra Unidad de TR era la de extraer todo injerto no funcionante independientemente de la causa y del tiempo trascurrido desde la implantación. Llegamos a efectuar en este período 108 trasplantectomías todas ellas, menos una, extracapsulares (9) y pese a que la corriente general de la mayoría de Unidades era la subcapsular, nuestras complicaciones fueron totalmente comparables a las obtenidas por esta última técnica con la ventaja de dejar una fosa ilíaca mucho más apta para recibir un ulterior $3^{\circ}$ ó $4^{\circ}$ trasplante. Las causas que originaron los óbitos fueron: una neumonía bilateral, una sepsis a Pseudomona, un status epiléptico con paro cardíaco y una pancreatitis.

Un caso muy especial vivido fue el de un receptor que falleció por fallo cardíaco a las pocas horas del implante. Se efectuó la trasplantectomía, se perfundió adecuadamente el injerto y pudo ser trasplantado en el Hospital 12 de Octubre de Madrid (10). Hasta donde conocemos es el primer caso de injerto renal que ha funcionado en dos receptores en forma sucesiva.

\section{TABLA I. INDICACIONES EN 681 NEFRECTOMÍAS.}

Donante riñon cadáver (bilat)

Donante riñon vivo.

Nefrectomía riñón homolateral atrófico

Trasplantectomías. 108

Tumor maligno parénquima renal

Tumor maligno de vías.

Tumores benignos renales.

Procesos infeccioso inflamatorios 128

Tuberculosis renal.

Poliquistosis (pre. T.R.)

Miscelánea:Traumas, vasculares,congénitas.....32

TOTAL
El quinto caso fue el único vivido en el resto de la serie y correspondió a un tumor urotelial de vías altas al que se practicó nefroureterectomía falleciendo al 19² día por su diabetes, sepsis urinaria, insuficiencia renal y trombosis venosa profunda.

Dentro del apartado de las complicaciones, considerando las mayores, se incluyen 47 casos $(8 \%)$ y se agrupan como indica la Tabla III. Su solución se ha basado en tratamientos conservadores en 32 y ha precisado reintervención en $15(2,5 \%$ sobre el total de cirugías).

Si analizamos la relación de las complicaciones con la patología tratada vemos como:

Las hemorragias severas con cuadro hipovolémico se han presentado en 5 casos. Tres de ellos siguieron a la cirugía de trasplantectomía en el postoperatorio inmediato por sangrado de alguna rama del pedículo vascular ligada incompletamente o por lesión directa de la pared arterial arteriosclerótica. Los otros dos fueron consecuencia de nefrectomías por cáncer renal y hamartoma de gran volumen. En los cinco casos la reintervención fue resolutiva y solucionó la situación.

Las complicaciones respiratorias afectaron a 11 pacientes con 7 neumonías, dos atelectasias y dos neumotórax, nefrectomizados por poliquistosis (dos), cáncer renal (tres), tuberculosis (dos), oncocitoma, tumor de vías e hidronefrosis. La vía de abordaje quirúrgico fue, en todos los casos, la lumbotomía posterolateral (LOPL) con resección subperióstica de la XII ${ }^{a}$ ú XI ${ }^{a}$ costilla $y$, en una ocasión, complementada con pararrectal baja.La apertura accidental de la pleura al resecar la XI $I^{a}$ costilla, aunque ocurrió en diversas ocasiones, sólo en dos precisó de drenaje torácico.

TABLA II. MORTALIDAD OPERATORIA (30 DÍAS): 588 NEFRECTOMÍAS.

\begin{tabular}{|l|l|}
\hline \multicolumn{1}{|c|}{ Causa } & \multicolumn{1}{c|}{ Intervención } \\
Neumonía bilateral & Trasplantectomía \\
Sepsis a Pseudomona & Idem. \\
Pancreatitis & Idem. \\
Status epiléptico & Idem. \\
Sepsis+Trombosis venosas & Nefroureterectomía por \\
& Tu.vías \\
\hline
\end{tabular}


El aparato digestivo fue la localización de 14 complicaciones destacando el íleo paralítico prolongado (siete) después de tres nefrectomías por cáncer renal, dos nefroureterectomías por tumor de vías y dos pielonefritis xantogranulomatosas (PXG). Las vías utilizadas fueron tres transperitoneales (en "chevron") y cuatro LOPL con dos pararrectales bajas. El ulcus sangrante se presentó en cuatro ocasiones precisando transfusiones, medidas de apoyo general y sonda nasogástrica ocasional después de dos nefroureterectomías por tumor de vías, una trasplantectomía y una PXG efectuadas por dos laparos medias, una LOPL y una pararrectal. Todas se resolvieron con medidas conservadoras.

El ileo obstructivo se presentó después de una nefroureterectomía por tumor de vías a la que se accedió por laparo media. Al sexto día postoperatorio presentó íleo de características obstructivas que se tuvo que resolver con reintervención y liberación de adherencias del intestino delgado.

TABLA III. COMPLICACIONES EN 588 NEFRECTOMÍAS.

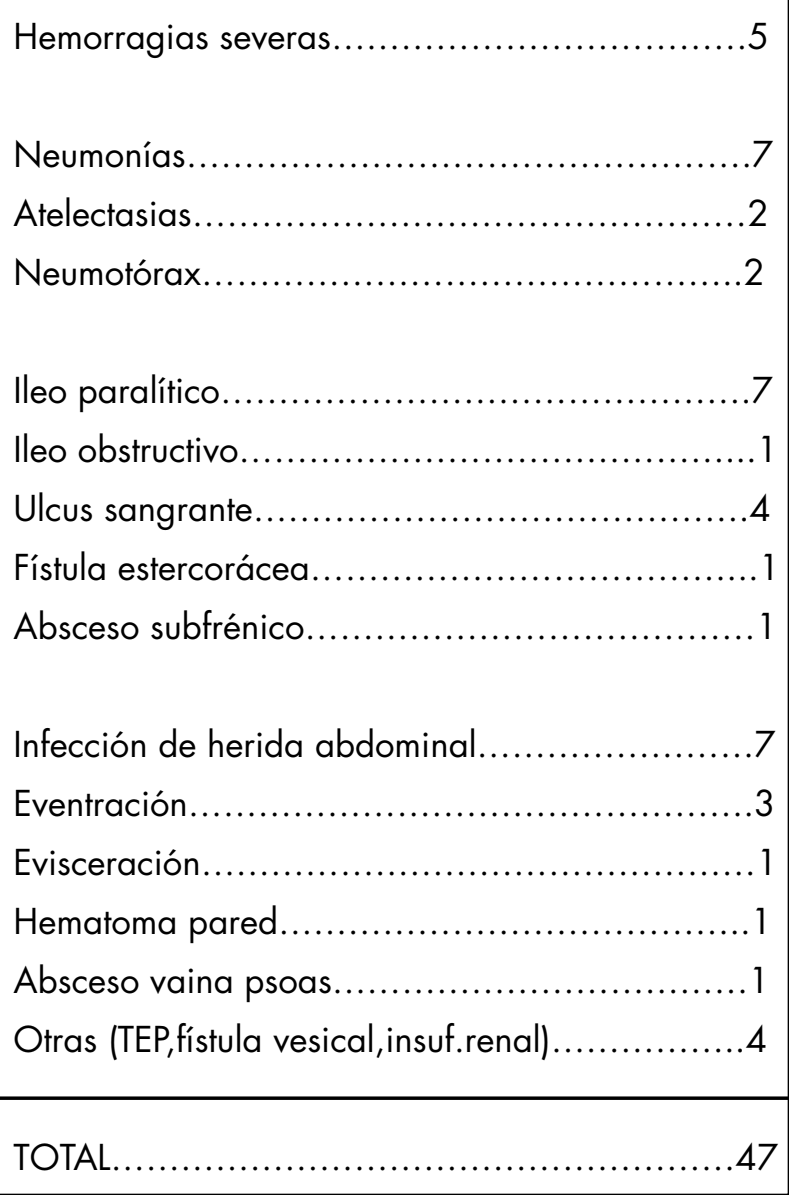

Después de una nefrectomía izquierda por LOPL en un caso de Malakoplaquia renal que infiltraba colon descendente se lesionó la pared intestinal y, aunque se suturó, en el postoperatorio presentó fístula estercorácea con escaso débito y que se solucionó con alimentación parenteral y sonda nasogástrica.

Un absceso subfrénico precisó reintervención para su evacuación después de una importante cirugía transperitoneal por laparo media realizada para extirpar una adenocarcinoma renal de más de $5 \mathrm{~kg}$ de peso(11).

La pared abdominal fue el lugar donde se localizaron siete abscesos subcutáneos después de siete nefrectomías por PXG y LOPL, con drenaje purulento que se mantuvo por espacio de 5 á 12 días. En este grupo se incluyen dos fístulas lumbares de origen profundo cuyo trayecto fue preciso extirpar. Otro caso fue un gran hematoma subcutáneo que fue desbridado después de una trasplantectomía por lesión de vasos epigástricos. Un punto clave en la valoración contrastada entre cirugía abierta y laparoscópica es la de las complicaciones de la pared abdominal, especialmente tras las lumbotomías y de aparición a medio/largo plazo. Es una realidad bien conocida que las lumbotomías ocasionan cuadros parestésicos e hipotonías musculares abdominales de la pared anterolateral del abdomen y que pueden lle-

\section{TABLA IV. DIAGNÓSTICOS DE LOS CASOS COMPLICADOS Y VIIAS DE ABORDAJE.}

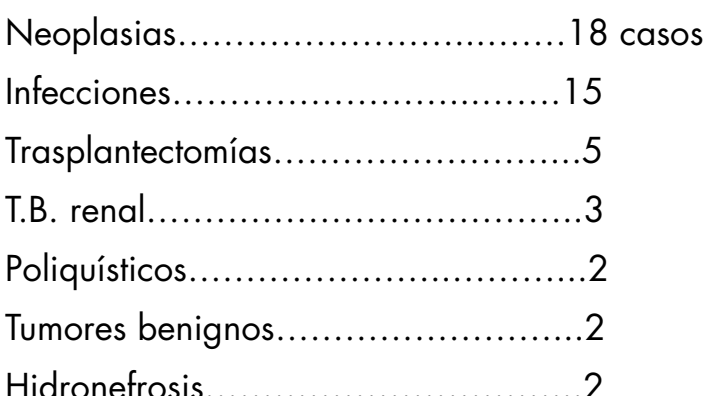

Vía L.O.P.L. *..............................27

L.O.P.L. + Pararrectal........................6

Transperitoneal................................9

L.V.P. * * .................................

*L.O.P.L. = Lumbotomía oblícua posterolateral

* L.V.P. $=$ Lumbotomía vertical posterior 
gar a la eventración y a precisar cirugía reparadora. No podemos certificar el número de pacientes con lumbotomía que han desarrollado una eventración a largo plazo por lo que recurrimos a señalar las que han precisado corrección quirúrgica y colocación de una malla. Entre los 2 y 4 años postoperatorios se ha reintervenido a tres pacientes todos ellos portadores de una LOPL.

Una nefroureterectomía por tumor de vías operada por laparotomía media acabó en evisceración tras un cuadro de ileo prolongado no resuelto con medidas conservadoras y que precisó reintervención, reducción y colocación de malla.

Finalmente, un absceso de la vaina del psoas precisó desbridamiento después de una nefrectomía por PXG.

Considerando la incidencia por patologías (Tabla IV) de las complicaciones nos encontramos que la etiología tumoral maligna es la que ha ocasionado el mayor número de las mismas, $18,141 \%$ de las complicaciones frente a un $30 \%$ de nefrectomías por dicha causa). Cuatro casos precisaron reintervención quirúrgica por hemorragia anemizante, absceso subfrénico, evisceración e íleo obstructivo.

El origen infeccioso-inflamatorio viene a continuación con $15,132 \%$ de las complicaciones cuando ese origen ha sido la causa del $24 \%$ de las nefrectomías). Su resolución ha precisado reintervención en 3 aunque nunca se ha debido realizar bajo indicaciones de "urgencia".

Las trasplantectomías, como ya se ha comentado antes, han supuesto un porcentaje relativo muy importante de morbilidad. Cinco casos $111,3 \%$ frente al $18,3 \%$ de nefrectomías) con el denominador común del cuadro hemorrágico (3 locales de la zona quirúrgica profunda, uno superficial y un ulcus de stress) han precisado 4 reintervenciones constituyendo, por tanto, el grupo de más alta morbilidad y, como también ya comentamos, de mortalidad y el que ha generado el índice más alto de reintervenciones.

Los nueve casos restantes que corresponden a patologías "benignas" (angiomiolipoma, poliquistosis, T.B. renal e hidronefrosis) completan el espectro habiendo generado un caso de hemorragia importante reintervenido después de la nefrectomía por un voluminoso hamartoma renal.

Considerando las vías de abordaje (Tablas IV y V), las LOPL han tenido el $61,7 \%$ de las complicaciones teniendo en cuenta que han supuesto el
$64,6 \%$ de los abordajes. La trasperitoneal ha contabilizado el $20,4 \%$ con el $28,5 \%$ de los accesos. En relación con las complicaciones de pared abdominal, el $80 \%$ hay que atribuírselas a las LOPL.

\section{COMENTARIO}

El análisis histórico de las nefrectomías por cirugía abierta nos ha llevado a considerar treinta y dos publicaciones con 10.825 casos comenzando por series publicadas en 1966 hasta nuestros días. Llama la atención el incremento de publicaciones en los últimos 20 años que se debe, sin duda, a la aparición de la nefrectomía laparoscópica y a la necesidad de series que contrasten múltiples aspectos entre las dos formas de abordar la exéresis del riñón.

Dentro de los artículos consultados, pero no cuantificados en la cifra al inicio mencionada, dos referencias muy importantes en cuanto al volumen que suponen como son las del Royal College of Surgeons inglés con un análisis de 17.755 nefrectomías, durante los años 1995-2002 (12) y las estadísticas de mortalidad operatoria por nefrectomías en U.S.A. (13) en el período 1994-1999 con 58.990 exéresis renales. Aunque bastantes series consultadas pueden referirse a nefrectomías por procesos concretos (tuberculosis (14), afecciones renovasculares (15), cán-

TABLA V. VÍAS DE ABORDAIE QUIRÚRGICO EN 681 INTERVENCIONES.

\section{Extraperitoneales}

L.O.P.L.:

- Con resección costal (XI-XII)

- Subcostal

- + pararrectal

- "Droller" 380

L.V.P. .7

Pararrectal 126

\section{Transperitoneales}

En "chevron" uni o bilat.........................92

Laparotomía media...............................74

En "estrella" 
cer renal (16-20), tumores de vías (21), donante vivo para trasplante... $(22,23)$, otras no establecen ninguna limitación ni por etiologías ni tamaño del órgano, hecho que debe tenerse en cuenta si pensamos en lo que se puede y se debe hacer por cirugía laparoscópica.

A grandes rasgos la mortalidad operatoria comprobada ha oscilado, en series importantes, entre el $0,3 \%(24)$ y el $4,2 \%(20)$ en los últimos cuarenta años. Debemos destacar ya las estadísticas, más arriba adelantadas, de dos países de primer orden que analizan, en su conjunto, 76.298 nefrectomías. En efecto la mortalidad en U.K. (17.308 casos) ha sido del $2,1 \%$ y la de USA (58.990 nefrectomías) del $3 \%$. Esas cifras promedio se deducen de series con porcentajes variables que pueden presentar índices más elevados en función de factores de riesgo añadidos (Tabla VI). Así se considera la suma del factor edad (>80 años)como responsable de cifras del $4,7 \%$ (12). La insuficiencia renal terminal grava las nefrectomías bilaterales previas al trasplante con una mortalidad del $3,6 \%$ pero si se añade a un factor edad (más de 50 años) llega hasta el 11,1\% (25). El nivel del centro quirúrgico valorado por el volumen de cirugías anuales puede elevar la mortalidad hasta un $3,2 \%$ en los con menor volumen frente a un $2,6 \%$ en los más experimentados (13).

Relacionado con este último parámetro se podría considerar la experiencia del cirujano que realiza las nefrectomías pero cuando ello ha sido considerado en algún trabajo (26) no parece que tuviera responsabilidad en el índice de mortalidad y, quizá, se podría aducir en el aspecto de morbilidad. La etiología tumoral, con el grado y extensión neoplásica local avanzados, puede alcanzar mortalidad entre $4,2 \%$ y $11,4 \%(20,27)$ ya que

TABLA VI. MORTALIDAD INFLUÍDA POR FACTORES DE RIESGO.

Edad. $4,7 \%$

Insuficiencia renal terminal $3,6 \%$

ld. + factor edad (>50 a) $11,1 \%$

Nivel del centro. $3,6 \%$

Neoplasia + extensión local........6,3\%-11,4\%

Comorbilidad vascular. $3,3 \%-25 \%$

Lesión esplénica(nefrec.izqda.)... $16,7 \%$

Nefrectomía de urgencia $9,0 \%$

Vía toraco abdominal $6,8 \%-18 \%$ muchas veces se exige la extirpación de segmentos de órganos vecinos como vena cava, colon, duodeno, hígado, cola de páncreas, diafragma, etc. Si la nefrectomía se efectúa sobre una celda renal con grave afectación inflamatoria, como los abscesos perinefríticos pueden producirse hasta un $30 \%$ de óbitos (28).

Cuando existe comorbilidad vascular importante se alcanzan cifras del 3,3\% pero si se asocia cualquier cirugía reparadora del riñón contra lateral puede llegar al 25\% (15). La lesión esplénica, que acaece en las nefrectomías transperitoneales izquierdas entre un $4,3 \%$ y un $24 \%$, grava notablemente la mortalidad hasta un $16,7 \%$ (29) reconociendo como factores de riesgo la edad (>65 a) la etiología tumoral maligna, la talla $>10 \mathrm{cms}$. y la localización en el hemirriñón superior. La indicación de urgencia casi triplica el índice de la cirugía electiva (12). Sobre la responsabilidad de la vía de abordaje no siempre se hace mención expresa pero debe señalarse la referencia de Dufour sobre la toracoabdominal que, en pacientes añosos, alcanza mortalidad entre 6,8\% y $18 \%(30)$ y la ya mencionada laparotomía media en las nefrectomías por tumor del riñón izquierdo.

Algunos trabajos valoran también peyorativamente el tiempo operatorio (24), y el tamaño tumoral (18). La nefrectomía de tumores en casos con metástasis podría elevar la mortalidad a un $4 \%-12 \%$ (27). Factores como: embolización previa a la cirugía, linfadenectomía o localización tumoral intrarrenal parecen no tener incidencia significativa salvo en la ya comentada lesión esplénica. En este sentido es destacable la serie personal de Giuliani de 200 nefrectomías ampliadas con L.A. realizadas por vía toracoabdominal o transperitoneal que incluía $24 \%$ de enfermos con $\mathrm{N}+$ sin incremento significativo de la mortalidad operatoria (19).

En nuestra opinión la realidad de sufrir cualquier tipo de patología que aconseje la nefrectomía ya introduce un factor variable pero cierto de riesgo que podemos constatar si la comparamos con la mortalidad referida tras las nefrectomías de donantes vivos para trasplante. En efecto, en tales circunstancias partimos de individuos "seleccionados", generalmente "jóvenes" y sin comorbilidades y, además, el riñón a extirpar no es asiento de patología significativa. Lo confirman las cifras que Najarian (31) publica en 1992 sobre más de 50.000 nefrectomías de donante vivo realizadas en 20 años entre USA y Canadá con una mortalidad global del 0,03\%. En nuestro país, la experiencia, en parte vivida, de las extracciones de vivo en el Hospital Clinic de Barcelona junto con las de nuestra propia unidad, unos 400 casos, arroja mortalidad "cero". 
Las causas primarias por las que se produce el fallecimiento reflejan algunas diferencias significativas si se agrupan como refleja la Tabla VII. Las afecciones cardio vasculares ocupan el primer lugar entre las nefrectomías por neoplasias (parénquima y vías) y por patología vascular severa (hasta el 35, $1 \%$ y $36,6 \%$ respectivamente) significativamente mayor que por patologías benignas o en pacientes con IRC $(27,2 \%$ y $27 \%)$.Dentro de este último grupo los cuadros sépticos, en general, tienen la responsabilidad del $45 \%$ de muertes lo que se explica por el conocido estado de inmunodepresión de estos enfermos. Son también considerables y graves los cuadros hemorrágicos en neoplasias y vasculopatías (16,6\%-25\%).

Resumiendo podemos decir que, en relación con las etiologías, las nefrectomías con más altos índices de mortalidad serían: las de tumores del riñón izquierdo intervenidos por laparotomía media o localmente avanzados y las realizadas sobre áreas perirrenales abscesificadas. En relación con la vía utilizada, sería la toracoabdominal la más agresiva en estrecha relación con las características locales tumorales que son, en definitiva, las causantes de su elección por el urólogo.

El análisis de la morbilidad generada por las nefrectomías choca con importantes obstáculos derivados de diferentes criterios en cuanto a la conceptualidad y severidad de las mismas, los apartados en que pueden ser clasificadas, la inclusión o no de complicaciones operatorias deslindadas de las postoperatorias, el índice de reintervenciones, el concepto de "hemorragia" y el criterio para la transfusión,etc. etc... En este sentido se expresa un reciente artículo de Stephenson (24) sobre la necesidad de proponer criterios para estandarizar las referencias de las complicaciones operatorias en la literatura. Con esta salvedad hemos seleccionado 16 de los 32 artículos de los que partíamos, que suponen 5.916 nefrectomías, que aunque distaban de ser ortodoxamente homogéneos nos permiten acercarnos a la realidad pretendida de "valorar" las complicaciones de esta cirugía. Así pues hemos considerado, siempre que ha sido posible y los autores lo han explicitado, complicaciones operatorias y postoperatorias, índice de reintervenciones, relación con el diagnóstico y, si se ha especificado, con la vía de acceso operatoria.

Las complicaciones operatorias son las que acaecen durante el acto quirúrgico y básicamente son lesiones accidentales sobre el órgano intervenido o sobre los órganos vecinos (Tabla VIIII). Sobre 2.195 nefrectomías refrendadas por la literatura dichas lesiones alcanzan un 7\%. La vena cava, los vasos del hilio renal, las venas lumbares o las propias del tumor muchas veces engrosadas y tortuosas pueden ser desgarradas, perforadas, lesionadas en el curso de la cirugía en cerca de la mitad de los casos. Vasos más alejados como el tronco hepático o esplénico pueden resultar también afectados. La pleura se lesiona en un $13 \%$ y el bazo hasta un $36 \%$ cuando se conjugan los factores de riesgo ya expresados más arriba. Las lesiones del tubo digestivo sólo alcanzan hasta un $1,4 \%$ y no son desdeñables las que refieren "diseminación tumoral operatoria" por masas abigarradas, adheridas $y$, quizá, en el límite de la operabilidad $(3,7 \%)$.

En el curso postoperatorio las complicaciones pueden ser agrupadas por patologías del órgano extirpado, por localización y etiología y considerar, también, su posible relación con la vía de acceso. En conjunto y sobre un análisis de 5.276 nefrectomías se han detectado 1.128 complicaciones $(19,5 \%)$ con valores extremos entre $8,3 \%$ de Rassweiler y $58,7 \%$ de Yarimizu. Se reparten según expresa la Tabla IX siendo, por este orden las más frecuentes, las com-

TABLA VII. CAUSAS PRIMARIAS MÁS IMPORTANTES DE MUERTE EN LAS NEFRECTOMIIAS.

\begin{tabular}{|l|l|l|l|l|}
\hline & $\begin{array}{l}\text { Por } \\
\text { Neoplasias }\end{array}$ & $\begin{array}{l}\text { Por } \\
\text { Vasculopatías }\end{array}$ & $\begin{array}{l}\text { Por IRC } \\
\text { terminal }\end{array}$ & Miscelánea \\
\hline Hemorragia & $16,6 \%$ & $25 \%$ & $9,2 \%$ & $4,2 \%$ \\
Infarto A.M. & 18,5 & 17 & - & - \\
Sepsis & 11,0 & - & 45 & 23 \\
Insuf.renal & 7,4 & 35 & - & 24 \\
Vasculares & 16,6 & 11,6 & 27 & 27,2 \\
\hline
\end{tabular}


plicaciones respiratorias (neumonías, atelectasias, neumotórax) con un $25,6 \%$, seguidas de las de la pared abdominal (dehiscencias, eventración, seromas, hematomas) con el 16,3\%, infecciosas (sepsis generales, abscesos profundos) con el $10,3 \%$ y las hemodinámicas (hemorragias, hipotensión, shock) con el $9,6 \%$. En un $2,1 \%$ (entre $0,58 \%$ y $7,5 \%$ ) ha sido precisa la reintervención causada básicamente por cuadros hemorrágicos $(57,7 \%)$ en los que, en una cuarta parte de ellos, fue obligada la esplenectomía; ileos obstructivos (17\%) y eventraciones $(15 \%)$ siguen en orden de frecuencia.

En cuanto al diagnóstico de los casos que generaron tales complicaciones (Tabla VII) predominan las neoplasias renales y de vías que constituyen el $61,4 \%$ de todos los diagnósticos seguidas de las causas infecciosas $(12, \%)$ y litiásico obstructivas $(5,1 \%)$. En conjunto las patologías "no malignas" suponen el $38,6 \%$.

Las vías operatorias utilizadas en los casos complicados expresan idéntica mayoría a favor de las vías transperitoneales (preferidas en cirugía de tumor renal) con un $76 \%$, con un $18 \%$ de lumbotomías y un $5,3 \%$ toracoabdominales. El grupo de pacientes intervenidos por lumbotomía oblicua es que que presenta un mayor índice de "abombamiento" abdominal con alteración de la imagen corporal y "molestias" en hemiabdomen homolateral que puede alcanzar a un $50 \%$ de los operados (32). A destacar que los intervenidos por lumbotomía vertical posterior no han presentado complicaciones postoperatorias por bien que los casos documentados han sido escasos (sesenta y uno). Por lo que se refiere a la lumbotomía oblicua sobre el flanco hay que matizar diferencias ya que ocasiona más problemas la lumbotomía a lo

\section{TABLA VIII. LESIONES INTRAOPERATORIAS MÁS}

\section{FRECUENTES}

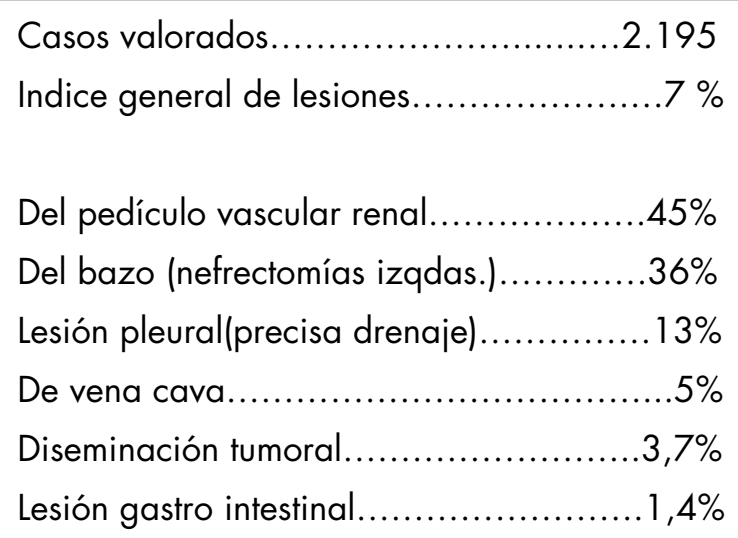

Bergmann-Israel que la lumbotomía posterolateral (sobre el trayecto de la XI ó XII ${ }^{\underline{a}}$ costilla.

La asociación tumor renal de hemirriñón superior izquierdo, de más de $10 \mathrm{cms}$ de diámetro e intervenido por laparotomía media tiene el más alto índice de morbilidad mayor por lesión esplénica y ulterior esplenectomía y se acompaña de una alta mortalidad.

\section{CONCLUSIONES}

De todo lo expuesto podríamos deducir que la morbimortalidad de la nefrectomía abierta, como siempre en cirugía, va a depender de factores intrínsecos del propio paciente y extrínsecos representados por el cirujano y centro en que es atendido.

Entre los primeros debemos considerar, por el análisis de la literatura, la edad, la etiología de la patología renal (tumores malignos, afecciones inflamatorias abscesificadas...) y la existencia de comorbilidades (insuficiencia renal terminal, vasculopatías severas...).

Entre los segundos, la experiencia del cirujano y el volumen de actividad de los centros, aunque muy escasamente explicitados en la mayoría de trabajos no deja de ser importante y, en cuanto a la vía seguida, se demuestra la toracoabdominal como la más agresiva y la lumbotomía "clásica" con efectos negativos sobre la imagen corporal de gran importancia en sujetos jóvenes.

TABLA IX. COMPLICACIONES POSTOPERATORIAS MÁS FRECUENTES.

Casos valorados..............................5.276

Indice general de complicaciones..........19,5\%

Del aparato respiratorio.....................25,6\%

De pared abdominal........................ 16,3\%

Infecciones generales/Abscesos............10,3\%

Hemorragia-Hipotensión-Shock...............9,6\%

De aparato digestivo.........................9,3\%

Cardiovasculares..............................8,8\%

Trombosis venosas + de FAVI................7,8\%

Mixtas.............................................6, $3 \%$ 
Sabemos pues lo que hasta el día de hoy hemos conseguido con la cirugía abierta y estos resultados son la referencia a tener en cuenta ante la progresiva implantación de la cirugía laparoscópica en nuestro centros.

Un análisis no exhaustivo sobre la nefrectomía laparoscopica nos ha llevado a revisar 30 artículos desde 1994 con un total de 2.582 nefrectomías realizadas, en cada caso, por centros de forma individual y 426 presentadas en experiencias multicéntricas y que no deberían ser sumadas a las anteriores por la participación de algunos centros tanto en el primer caso como en el segundo.

En el momento actual se reconocen dos posibles modalidades para la nefrectomía laparoscópica: transperitoneal y retroperitoneal, con la posibilidad complementaria de la "mano asistida".

Tras 14 años desde la primera descripción de Clayman de nefrectomía transperitoneal (33) y, de 12 , de la retroperitoneal $(34,35)$, el horizonte de esta cirugía se ha propuesto reproducir los resultados de las vías abiertas con menor morbimortalidad que aquella y cumpliendo las exigencias que, por ejemplo, la cirugía oncológica impone. Como toda técnica emergente se le debe conceder, en la curva de aprendizaje, una mayor incidencia de problemas que la práctica y experiencia irán limando. Por esta misma circunstancia es admisible una cautelosa selección de casos en los comienzos de todas las unidades que practican esta cirugía. Las llamadas "patologías benignas" y los tumores renales localizados no tributarios de exéresis parcial forman el cuerpo principal de sus indicaciones, sin olvidar la progresiva aceptación de esta vía, muchas veces mano asistida, en las nefrectomías de donante vivo para trasplante. Sin embargo, la progresiva experiencia junto con la mejora del instrumental disponible, está haciendo que los centros adelantados en esta cirugía amplien sus indicaciones. Así ya, en ellos, no se limita el tamaño de los tumores renales (36) o, incluso, la presencia de trombo venoso en vena renal (1). La obesidad ha dejado de representar una contraindicación absoluta $y$, aunque se reconoce una mayor morbilidad que en los no obesos, sus resultados son comparables a los de la cirugía abierta $(37,38)$. La nefrectomía en niños, incluso de muy poco peso, también ha sido realizada satisfactoriamente (39) lo mismo que en pacientes grávidas (40). En cualquier caso, sin embargo, hay que apelar a la responsabilidad de cada cirujano frente a esta nueva modalidad operatoria porque, como siempre, no todo son excelencias $y$, también aquí, encontramos mortalidad y morbilidad. Ciertamente la mortalidad "confesada" por los autores es muy baja. Según esos trabajos oscila entre el
$0 \%$ de la mayoría hasta el 1,2\% (41-43). Tengamos presente que casi la mitad de todos los casos han sido nefrectomías por procesos "benignos" y que todos los fallecimientos comunicados han sido por nefrectomías de cáncer renal.

Las complicaciones intraoperatorias se mueven entre un $6,9 \%$ y $9,7 \%(44,45)$ y llama la atención una referencia por tener un índice muy bajo (sólo un $3 \%$ ) en 111 nefrectomías de donantes para trasplante realizadas en el $47 \%$ de los casos por "Residentes" (46) por laparoscopia mano asistida. En este mismo trabajo se mencionan dos "pérdidas del injerto" ocurridas en sus primeros treinta casos.

Estas complicaciones intraoperatorias afectan a los vasos renales y vena cava, principalmente, hasta en el $68 \%$ de todas las complicaciones intraoperatorias. Las dificultades de disección de los vasos a nivel del hilio constituye su causa más frecuente. Algún autor (47) ha realizado en estos casos la "ligadura en bloque" (26 pacientes) sin fistulas arteriovenosas a largo plazo.

El resto de las lesiones se producen sobre órganos parenquimatosos (hígado, bazo) en el 13,7\% o intestino (duodeno, delgado o colon) en el 15,6\%. Como consecuencia de muchas de estas lesiones aparece la necesidad de reconversión en cirugía abierta lo que viene a suponer del $0 \%$, en escasas referencias (el riesgo "cero" no existe), (48) al 8,2\% (49) de todas las nefrectomías, pero si consideramos el porcentaje sólo sobre las complicaciones vemos que alcanza de un $25 \%$ a un $60 \%$ de los casos siendo observable una clara diferencia entre las "primeras" y "segundas" épocas de las diferentes unidades. En un estudio multicéntrico americano (50) se realizaron el $71 \%$ de las conversiones en la llamada "primera" época.

Otras veces, la "posibilidad" de una conversión se acentúa ante patologías renales y perirrenales infecciosas en el límite de la indicación. Eraky (51) comunica haber convertido dos de tres pielonefritis xantogranulomatosas.

Las complicaciones mayores ocurridas en la cirugía laparoscópica suponen, en los artículos consultados, en torno al $10 \%$ de los casos. A destacar, sin embargo, como un centro de la gran experiencia como la Cleveland Clinic y tras 231 nefrectomías por cáncer renal tiene por encima del $20 \%$ de complicaciones tanto en tumores $\mathrm{T} 1$ como T2. En cambio, el estudio multicéntrico americano dirigido por Gill (50) con 185 casos nefrectomizados por causas mayoritariamente "benignas" sitúa las complicaciones alrededor del $16 \%$. 
La pormenorización de estas complicaciones indica que el $60 \%$ de las mismas lo constituyen los problemas de pared (hematomas, hernias, enfisema) y las hemorragias tardías con un $17 \%$ cada una de ellas seguidas de las complicaciones digestivas (ileos) con el $14 \%$ y respiratorias (básicamente neumotórax) con un $11 \%$.

También han sido objeto de crítica la posible implantación de metástasis en los trayectos de acceso, recidiva local por diseminación tumoral en el manejo y extracción tumoral o morcelación de la masa renal con imposibilidad de estadiaje. La revisión de las primeras ha detectado sólo 5 casos, dos después de nefroureterectomías y tres tras nefrectomía radical (52).

Los tiempos operatorios que inicialmente presentaban una clara ventaje de las cirugías abiertas se han ido reduciendo hasta no llegar a constituir "per se" factor adverso decisorio.

Las posibles interferencias de la cirugía laparoscópica con las funciones ventilatoria y hemodinámica deberían ser cuidadosamente valoradas en casos de pacientes con comorbilidades en esos aparatos. Con todo parece haberse establecido que la retroperitoneoscopia tendría objetivas ventajas sobre el acceso transperitoneal (49).

Las ventajas en estancias, consumo analgésico, convalescencia y reintegración laboral inmediata, en estos momentos, están totalmente fuera de duda.

Podríamos pues concluir que la actual cirugía laparoscópica va acercándose cada vez más a conseguir el espectro de indicaciones que antes eran el objeto de la nefrectomía abierta en los centros de mayor experiencia. Hay que admitir una curva de aprendizaje imprescindible y sus limitaciones vendrán dictadas por el propio criterio y honestidad de cada grupo tanto en lo que se refiere a no exceder su indicación en patologías "benignas" (pielonefritis o hidronefrosis atróficas) en las que puede estar, incluso, dudosamente indicada la cirugía, como el aventurar un excesivo riesgo en cuadros infecciosos característicos como las pielonefritis xantogranulomatosas o las grandes masas renales.

En cualquier caso me parece que el impulso a seguir este camino han de tomarlo quienes ya tienen una asentada experiencia en cirugía abierta con unos conocimientos que van a ser sumamente útiles en su aplicación a una modalidad operatoria que se verá plenamente implantada en el actual siglo XXI.

La presencia de autores españoles en la literatura asequible a través de Med Line sobre el tema que nos ha ocupado es algo escasa desde las primeras publicaciones de Carlos Rioja con la primera nefrectomía realizada en nuestro País (53) y el estudio experimental de Valdivia (54) ambos en 1992. A destacar las aportaciones de Sánchez de Badajoz (55), la revisión de $M^{a}$ F. Lorenzo sobre nefrectomías en niños (56), las aportaciones del grupo de Fundación Puigvert (57-59) y, últimamente del grupo Virgen de la Arrixaca de Mariano Pérez Albacete (60). A buen seguro que, en breve, veremos sucederse nuevos artículos de los ya numerosos grupos que en España están realizando esta técnica.

\section{BIBLIOGRAFÍA y LECTURAS RECOMENDADAS (*lectura de interés $y^{* *}$ lectura fundamental)}

1. SAVAGE, S.J. y GILL, I.S.: "Laparoscopic radical nephrectomy for renal cell carcinoma in a patient with level I renal vein tumour thrombus". J. Urol., 163, 1243, 2000.

2. MURPHY, L.J.T.: "The History of Urology". Springfield, Illinois. Ch. C.Thomas, pp 235-271, 1972.

3. CABOT, H.: "The operative approach for malignant tumours of the kidney". J.Urol., ,14, 261, 1925.

4. YOUNG, H.H. y DAVIS, D.M.; "Young's practice of Urology based on a study of 12.500 cases". Philadelphia: W.B. Saunders Co., vol.2, , 284, 1926.

5. POUTASSE, E.F.: "Anterior approach to upper urinary tract surgery”. J.Urol., 85,199, 1961.

6. JUDD, E.S. y HAND, J.R.: "Hypernephroma". J.Urol.,22, 10, 1929.

7. ROBSON, C.J.; CHURCHILL,B.M.; y ANDERSON, W.:'The results of radical nephrectomy for renal carcinoma". J.Urol., 101,297, 1969.

8. BALLESTEROS, J.J.; GUZMAN, A. y CORTADELLAS, A.: “Análisis de las anomalías, patologías y yatrogenias del injerto renal: Valoración de la cirugía de banco". Arch. Esp. Urol.,48,266,1995.

*9. BALLESTEROS, J.J.:’Trasplantectomía extracapsular sistemática del injerto renal no funcionante". Actas Urol. Esp.,18 supl.,532, 1994.

*10. GUZMAN, A.; POLO,G.; BALLESTEROS, J.J. y LEIVA, O.: "Reutilización de un riñón trasplantado por un $2^{\circ}$ receptor"Actas Urol. Esp.,21,692, 1997.

11. BALlESTEROS, J.J. y LLORETA, J.: "Nefrectomía de un hipernefroma gigante (5.150 grs)". Actas Urol. Esp.,26, 432,2002.

*12. NUTTALL,M.; CATHCART, P.; VAN DER MEULEN, J. y cols.:"A description of radical nephrectomy practice and outcomes in England 1995-2002”. B.J.U. International,96,58, 2005. 
**13. BIRKMEYER, J.D.; SIEWERS, A.E.; FINLAYSON, E.V.A. y cols.: "Hospital volume and surgical mortality in The United States". N.Engl. J.Med.,346,1128, 2002.

14. FLECHNER, S.M. y GOW, J.G.: "Role of nephrectomy in the treatment of non functioning or very poorly functioning unilateral tuberculous kidney". J.Urol., 123,822,1980.

*15. FRANKLIN, S.S.; YOUNG, D.D.; MAXWELL, M.H. y cols.: "Operative mortality and morbility in renovascular diseaese". JAMA,231,1148, 1975.

16. THOROADSEN, A.; GUDBJARTSSON, T.; JONSSON, E. y cols.:"Operative mortality after nephrectomy for renal cell carcinoma". Scand. J. Urol. Nephrol., 2003,37, 507-511.

*17. SWANSON, D.A. y BORGES, P.M.: "Complications of transabdominal radical nephrectomy for renal cell carcinoma". J.Urol.,129,704, 1983.

*18. MEJEAN, A.; VOGT,B.; QUAZZA, J.E. y cols.:"Mortality and morbility after nephrectomy for renal cell carcinoma using a transperitoneal anterior subcostal incision”. Eur.Urol.,36,298,1999.

*19. GIULIANI,L.; GIBERTI, C.; MARTORANA, G. Y cols.:"Radical extensive surgery for renal cell carcinoma: Long term results and pronostic factors". J.Urol.,148,468, 1990.

*20. CHATELAIN, C.; RICHARD, F. y SCHAETZ, A.: "Surgical treatment of renal cell carcinoma. Current possibilities and results evaluated on series of 507 operated patients". En Therapeutic Progress in Urological Cancers. Alan R. Liss Inc., pp711,1989.

21. RASSWEILER, J.J.; SCHULZE, M.; MARRERO, R. Y cols.:"Laparoscopic nephroureterectomy for upper urinary tract transitional cell carcinoma: Is it better than open surgery?". Eur. Urol.,46,690,2004.

22. OPPENHEIMER, F.; ROSSICH,E. y RICART,M. J.:"Evolución del donante después de la nefrectomía.Morbimortalidad operatoria y postoperatoria e impacto a largo plazo de la nefrectomía”. Arch. Esp.Urol.,58,543,2005.

23. BLOHME, I.; FEHRMAN, I. y NORDEN, G.: "Living donor nephrectomy". Scand. J.Urol.Nephrol.,26,149, 1992.

*24. STEPHENSON, A.J.; ARI-AKIMI, A.; SNYDER, M.E. y cols.:"Complications of radical and partial nephrectomy in a large contemporary cohort". J.Urol,171,130., 2004.

25. YARIMIZU,S.H.; SUSAN, L.P.; STRAFFON, R.A. y cols.:"Mortality and morbidity in pretrasplant bilateral nephrectomy"Urology,XII,55, 1978.

*26. SCOTT, R.F. y SELZMAN, H.M.: "Complications of nephrectomy. Review of 450 patients and a description of a modification of the transpewritoneal approach”. J. Urol. 95, 307, 1966.
*27.BEISLAND,Ch.; MEBDY, P.Ch.; SANDER, S. y cols.:"Nephrectomy. Indications, complications and postoperative mortality in 646 consecutive patients".Eur.Urol., 37,58, 2000.

28.GONZALEZ SERVA,L.; WEINERTH, J.L. y GLENN, J.F.:"Minimal mortality of renal surgery".Urology, IX,253, 1977.

*29. COOPER, Ch.S.; COHEN, M.B. y DONOVAN,J. F.:"Splenectomy complicating left nephrectomy". J.Urol.,155,30, 1996.

30.DUFOUR, B.; CHOQUENET,Y. y LEPAGET,T: "La voie $\mathrm{d}$ 'abord antérieure trans pèritoneale sous costale du rein"J. d'Urol.,87,153,1981.

*31.NAJARIAN, J.S.; CHAVERS, B.M. y MacHUGH, L.E.:"20 years or more of follow-up of living kidney donors".Lancet, 1354, 1992.

32. CHATERJEE, S.; NAM,R,; FLESHNER, N. y cols.:"Permanent bulge is a consecuence of flank incision for radical nephrectomy in one half of patients". Urol. Oncol.,22,36, 2004.

*33.CLAYMAN, R.V.; KAVOUSSI,L.R.; SOPER, N.J. y cols.: "Laparoscopic nephrectomy: Initial case report". J.Urol.,146,278, 1991.

34.KERBL, K.; FIGENSHAU, R.S.; CLAYMAN, R.V. y cols.."Retroperitoneal laparoscopic nephrectomy: Laboratory and clinical experience". J. EndoUrol.,7, 23, 1993.

35.GAUR, D.D.; AGARWAL, D.K. y PUROMIT, K.C.:" Retroperitoneal laparoscopic nephrectomy: Initial case report”. J.Urol.,149, 103,1993.

*36. STEINBERG, A.P.; FINELLI,A.;DESAI,M.M. y cols.: "Laparoscopic radical nephrectomy for large renal tumours". J.Urol.,172,2172, 2004.

*37.STOLLER, A.J.W.; MENG, M.V.; MASTER,V. A. y cols.:"Differences in complications and outcomes for obese patients undergoing laparoscopic radical, partial or simple nephrectomy". J.Urol., 172,2287, 2004.

38.KAPOOR,A.; NASSIR, A.; CHEW, B. y cols.: "Comparison of laparoscopic radical renal surgery in morbidly obese and non obese patients". J.Endourol.,18,657, 2004.

*39. MULHOLLAND, T.L.; KOPP, B.P. y WONG, G.C.: "Laparoscopic renal surgery in infants 10 $\mathrm{kg}$ or less".J.Endourol., 19,397, 2005.

40.SAINSBURY, D.C.; DORKIN， T.J.; MAC PHAIL, S. y cols.:"Laparoscopic radical nephrectomy in firts trimester pregnancy". Urology,64, 1231, 2004.

*41.SIQUEIRA, Th; KUO,R.L.;GARDNER, Th.A. y cols.: "Major complications in 213 laparoscopic nephrectomy cases: The Indianapolis experience”. J.Urol.,168,1361, 2002.

42.PORTIS, A.J.; YAN-YAN; LANDMAN, J. y cols.:"Long-term follow-up after laparoscopic radical nephrectomy”. J.Urol.,167,1257, 2002. 
*43. CADEDDU, J.A.; ONO,Y.; CLAYMAN, R.V. y cols.:'Laparoscopic nephrectomy for renal cell cancer: Evaluation of efficacy and safety. A multicenter experience"Urology, 52,773, 1998.

44. ABBOU, C.C.; GASMAN, C.D.; HOZNEK,A. y cols.:"Retroperitoneal vs open radical nephrectomy". J.Urol.,161,1776,1999.

45. ONO, Y.; KINUKAWA,T.; HATTORI, R. y cols.: "The long-term outcome of laparoscopic radical nephrectomy for small cell carcinoma". J.Urol., 165,1867, 2001.

46. HOLLENBECK, B.K.; SELFMAN,B.D. y WOLF, J.S.: " Clinical skills acquisition for hand assisted laparoscopic donor nephrectomy".J.Urol., 171,35, 2004.

47. RAPP, D.E.; ORVIETO, A.; GERBER, G.S. y cols.:" En bloc stapling of renal hilum during laparoscopic nephrectomy and nephroureterectomy". Urology, 64, 655, 2004.

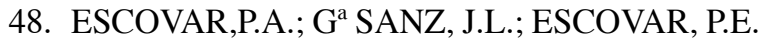
y cols.:"Nefrectomía endoscópica retroperitoneal”. Arch.Esp.Urol.,55,696, 2002.

*49. NADU, A.; EKSTEIN, P.; SZOLD, A. y cols.: "Ventilatory and hemodinamic changes during retroperitoneal amd tramnsperitoneal laparoscopic nephrectomy: A prospective real -time comparison”. J. Urol.,172,1013, 2005.

**50. GILL, I.S.; KAVOUSSI,L.R.; CLAYMAN,R.V. y cols.:"Complications of laparoscopic nephrectomy in 185 patients: A multiinstitutional review". J. Urol.,154,479, 1995.

51. ERAKY, I.; EL-KAPPANY, H.; SHAMAA. M.: y cols.:'Laparoscopic nephrectomy: An established routine procedure". J. Endourol.,7, S 64, abstract RT.I-4, 1993.
52. TSIVIAN, A. y SIDI, A. A.: "Port side metastases in urological laparoscopic surgery" J.Urol.,169,1213, 2003.

*53. RIOJA, C.; MINGUEZ, J.M.; BLAS, M. y cols.: "Nefrectomía laparoscópica: Caso report". Actas Urol. Esp., 16,544, 1992.

*54. VALDIVIA, J.G.; VILORIA,A.; GONZALEZ,N. y cols.:"Nefrectomía laparoscópica: Modelo quirúrgico experimental". Actas Urol. Esp. 16,169174, 1992.

55. SANCHEZ DE BADAJOZ, E. y JIMENEZ,A.:" Iniciación a la nefrectomía laparoscópica”. Arch. Esp.Urol.,55,425, 2002.

56. LORENZO M.F. y GONZALEZ R.: "Nefrectomía laparoscópica en niños: Vía transperitoneal versus retroperitoneal".Arch.Esp. Urol.,56,401,2003.

57. ROJAS, D.; ROSALES, A.; PALOU, J. y cols.: "Nefrectomía laparoscópica bilateral por cáncer renal".Arch.Esp.Urol.,57, 844,2004.

58. ROSALES, A.; SALVADOR, J.; DE GRAEVE, N. y cols.: "Clamping of the renal artery in laparoscopic partial nephretomy:An old device for a new technique". Eur.Urol.,47,98, 2005.

59. GUIRADO, F. C.; DIAZ, J. M.; ALCARAZ, A. y cols.: "The living kidney donor:Laparoscopic versus open surgery". Nefrología,25 supl.2, 62, 2005.

60. LOPEZ, P.; PRIETO, A.; GOMEZ, G. y cols.: "Nefrectomía radical laparoscópica asistida por la mano frente a nefrectomía abierta en el tratamiento del carcinoma de células renales clínicamente localizado. Estudio comparativo". Arch. Esp. Urol., 57, 833, 2004. 